\title{
The Significance of Neutrophil-to-Lymphocyte Ratio and Platelet-to-Lymphocyte Ratio in Acute Low Tone Sensorineural Hearing Loss
}

\author{
Keon-Ho Kim, Byung Hun Kim, Seungyeol Lee, \\ Jae Ho Chung $\mathbb{D}$, Hayoung Byun, and Seung Hwan Lee \\ Department of Otorhinolaryngology-Head and Neck Surgery, Hanyang University College of Medicine, Seoul, Korea \\ 급성 저음역 감각신경성 난청에서 호중구-림프구 비율 및 혈소판-림프구 비율의 의의 \\ 김건호 · 김병훈 · 이승열 · 정재호 · 변하영 · 이승환 \\ 한양대학교 의과대학 이비인후-두경부외과학교실
}

Received April 22, 2020

Revised July 22, 2020

Accepted August 3, 2020

Address for correspondence

Seung Hwan Lee, MD, PhD

Department of Otolaryngology-

Head and Neck Surgery,

Hanyang University

College of Medicine,

222 Wangsimni-ro, Seongdong-gu,

Seoul 04763, Korea

Tel $+82-31-560-2368$

Fax $+82-31-566-4884$

E-mail shleemd@hanyang.ac.kr
Background and Objectives Acute low tone sensorineural hearing loss (ALHL), an acuteonset hearing loss limited to low tone, was thought to be a subtype of sudden sensorineural hearing loss (SSNHL) but also considered as new disease entity because it shows quite different symptoms, progress, and prognosis. More recently, however, it is thought that SSNHL results from chronic inflammation and thrombosis. Some studies have reported that neutrophil-to-lymphocyte ratio (NLR) and platelet-to-lymphocyte ratio (PLR) were high in SSNHL patients, and that they were significant as prognostic factors. The aim of this study was to evaluate the significance of NLR and PLR in ALHL.

Subjects and Method From January 2009 to June 2019, we retrospectively studied 58 patients who were diagnosed with ALHL. Characteristics of patients such as sex, age, symptoms and signs, the results of serologic test and pure tone audiometry were evaluated for recovery and for recurrence. Also, we selected 58 people with the same age as control group.

Results A total of 167 patients were identified, of whom a half was diagnosed with ALHL and the other half with were the control group. Among the 58 patients, the mean age was $38.0 \pm 14.5$ years old, and $10(17.2 \%)$ patients were male and $48(82.8 \%)$ patients were female. Among the patients, $35(60.3 \%)$ were hospitalized and $23(39.7 \%)$ were outpatients. For recovery, $38(65.5 \%)$ patients fully recovered while $11(19.0 \%)$ partially recovered, and $9(15.5 \%)$ did not recover. Additionally, $16(27.6 \%)$ patients recurred later with similar symptoms. Between the patient group and control group, there were significant differences in the total white blood cell count, neutrophil count, NLR and PLR ( $p=0.015,0.001,0.002$, and 0.025 ), but there was no significant differences between the recovery group and non-recovery group in any laboratory findings. Also, NLR and PLR showed no significant differences between the recurred group and non-recurred group. Conclusion NLR and PLR in ALHL patients were relatively high compared to the control group, but there were no significant differences between the recovery group and non-recovery group. Furthermore, there was no correlation between NLR and PLR with recurrence. High NLR and PLR values in ALHL patients might reflect its inflammatory etiology, but there is lack evidence for them to serve as prognostic factors.

Korean J Otorhinolaryngol-Head Neck Surg 2020;63(12):558-63

Key Words Hematologic test · Pathophysiology $\cdot$ Sensorineural hearing loss.

This is an Open Access article distributed under the terms of the Creative Commons Attribution Non-Commercial License (https:/creativecommons.org/licenses/by-nc/4.0) which permits unrestricted non-commercial use, distribution, and reproduction in any medium, provided the original work is properly cited. 


\section{서 론}

돌발성 난청(sudden sensorineural hearing loss)은 일반적 으로 3일 이내에 발생한 3 개 이상의 연속된 주파수에서 $30 \mathrm{~dB}$ 이상의 청력손실을 의미한다. ${ }^{1)}$ 이러한 돌발성 난청의 정확한 병인은 아직 밝혀져 있지 않지만 최근에는 만성 염증과 혈전 에 의한 허혈이 원인으로서 제시되고 있고, 이에 전신적 염증 상태 및 혈전 발생에 대한 표지자로서 호중구-림프구 비율 (neutrophil-to-lymphocyte ratio, NLR)과 혈소판-림프구 비율(platelet-to-lymphocyte ratio, PLR)이 최근 여러 논문 들에서 조명되고 있다. ${ }^{2)} \mathrm{NLR}$ 은 이미 여러 고형 종양이나 폐 색전증, 만성폐쇄성폐질환 등에서 예후인자로 사용되고 있으 며, PLR과 더불어 류마티스 관절염, 전신성홍반성루푸스, 베 체트병 등의 전신 염증성 질환들에서는 그 질병활성도를 예 측하는 인자로서도 조명되고 있다. ${ }^{3-8)}$ 돌발성 난청에 있어서는 Ulu 등 ${ }^{9}$ 이 진단과 회복 정도를 예측하는 인자로서 NLR이 유 용하다고 하였고, Yi 등(1)은 NLR 외에 PLR도 추후 돌발성 난청의 회복에 대한 예측인자로 고려되어야 한다고 하였다.

한편, 급성 저음역 감각신경성 난청(acute low tone sensorineural hearing loss, ALHL)은 저음역에 국한되어 급성으 로 발생하는 청력손실을 의미하며, 돌발성 난청의 한 종류로 생각되지만 그 증상, 경과, 예후 등에서 다른 특성을 보이기 때문에 새로운 질병으로 간주되기도 한다. ${ }^{11)}$ 이에 본 연구에 서는 ALHL로 치료받았던 환자들을 대상으로 임상 양상, 검 사 결과 및 예후를 비교 분석하여 호중구-림프구 비율과 혈 소판-림프구 비율이 돌발성 난청의 경우에서와 마찬가지로 진단 및 예후 예측에 의의를 가지는지 알아보고자 하였다.

\section{대상 및 방법}

2009년 1월 2019년 6월까지 한양대학교 구리병원에서 급 성 저음역 감각신경성 난청으로 진단받았던 58 명의 환자들을 대상으로 하였으며, 증상, 혈액검사 및 청력검사 결과, 호전 여 부, 재발 여부 등에 대해 후향적으로 의무기록을 조사하였다. 초진 시 순음 청력 검사상 $250,500 \mathrm{~Hz}$ 의 저주파 영역에서 합 계 $50 \mathrm{~dB} \mathrm{HL}$ 이상의 일측성 감각신경성 난청을 보이며, 2000, $4000,8000 \mathrm{~Hz}$ 의 청력 역치의 합이 $60 \mathrm{~dB} \mathrm{HL}$ 이하의 정상 청 력을 보이는 경우를 급성 저음역 감각신경성 난청으로 진단하 였다. ${ }^{12,13)}$ 내원 시 급성 감염 증상이 있었던 환자들과 본원 내 원 전에 타원에서 급성 저음역 감각신경성 난청을 진단받고 스테로이드를 이미 복용했던 환자들은 혈액 검사 중 총 백혈 구 수 및 호중구분율, 림프구분율에 영향을 줄 수 있어 제외 하였다. 또한, 이전에 이미 메니에르병으로 진단되었거나 추적
관찰 시 메니에르병으로 진단된 환자 및 내원 시 안진이 관찰 되었던 환자들도 제외하였다. 또한 비교 분석을 위해 58 명의 대조군을 선정하였는데, 본원에서 비중격 교정술을 위해 수 술 전 혈액검사를 했던 환자들 중에 환자군과 성별과 연령이 같고, 기저질환이 없으며, 급성 감염 증상이 없었던 환자들을 대상으로 하였다. 이 연구는 한양대학교 구리병원 윤리위원 회 승인을 받아 진행되었다(IRB No. 2020-05-028).

돌발성 난청에서는 청력 회복의 기준으로 Siegel의 분류가 소개되어 있으나, 아직 급성 저음역 감각신경성 난청에서는 청력 회복의 기준이 정립되어 있지 않은 실정이다. ${ }^{10,14)}$ 따라서 본 연구에서 저자들이 완전회복, 부분회복, 비회복의 기준을 설정하였다. 최종 순음청력검사에서 $250,500 \mathrm{~Hz}$ 의 저주파 영 역에서 합계 $40 \mathrm{~dB} \mathrm{HL}$ 이하로 청력 호전을 보인 경우를 완전 회복군, 최종 저주파 영역 합계가 최초 저주파 영역 합계와 같 거나 그보다 증가한 경우를 비회복군, 그리고 그 사이에 해당 하는 군을 부분회복군으로 분류하였다. ${ }^{15)}$ 또한, 본 연구에서 재발이라 함은 초기 발병 시 모든 치료가 끝난 이후 동측 귀 의 난청 증상으로 재내원한 경우로, 실제 순음청력검사에서 마지막 검사 결과와 비교하여 청력역치 상승이 확인된 경우 로 정의하였다.

치료 방법에 있어 모든 환자에서 경구 고용량 스테로이드를 처 음 내원한 날부터 5일간 prednisolone $60 \mathrm{mg} / \mathrm{day}$ (체중 $60 \mathrm{~kg}$ 이하인 경우 $1 \mathrm{mg} / \mathrm{kg} / \mathrm{day}$ ) 사용하였고, 이후 1 주간에 걸쳐 서 서히 감량하였다. 총 12 일간의 경구 고용량 스테로이드 치료 가 끝난 후에도 청력 호전이 없었던 환자에서는 이뇨제를 처 방하거나 고실내 스테로이드 주입술을 시행하였다. 이뇨제를 처방한 경우에 thiazide는 $50 \mathrm{mg} / \mathrm{day}$, amiloride는 $10 \mathrm{mg} /$ day의 용량으로 처방하였고 두 가지 종류를 같이 사용하였다. 고실내 스테로이드 주입술은 2 주간 4 회에 걸쳐 시행하였으며, 약 0.3 0.5 mL의 dexamethasone을 고막의 전상부에 천자 바늘을 통하여 주입하였다. ${ }^{16)}$ 혈액검사는 처음 환자 내원 시 경 구 스테로이드 복용을 시작하기 전에 시행하였으며, 재발군의 경우에는 처음 발병 시의 혈액검사 결과를 사용하였다.

통계 분석은 SPSS version 21.0 software(IBM Corp., Armonk, NY, USA)를 이용하였다. 독립표본 t검정 방법을 이용 하여 두 군 간의 자료들을 비교하였으며, $p$-value가 0.05 이 하인 경우 통계학적으로 유의한 것으로 간주하였다.

\section{결 과}

총 58 명의 환자군과 58 명의 대조군이 연구에 포함되었다. 환자군 58 명의 평균 연령은 $38.0 \pm 14.5$ 세였고, 이중 남성이 10 명 (17.2\%), 여성이 48명(82.8\%)이었다. 환자들의 평균적인 증상시 
작부터 치료시작까지의 기간은 $5.2 \pm 6.1$ 일이었다. 동반증상으 로 이명과 어지럼증 모두 호소했던 환자는 10명(17.2\%)이었으 며, 이명만 호소했던 환자는 25명(43.1\%), 어지럼증만 호소했 던 환자는 5명(8.6\%), 나머지 18명(31.0\%)은 동반증상이 없었 다. 치료방법으로는 모든 환자가 경구 스테로이드를 사용하였 으며, 이뇨제를 같이 사용했던 경우는 7명(12.1\%), 고실내 스테 로이드 주입술을 병행했던 경우는 13명(22.4\%), 이뇨제와 고 실내 스테로이드 주입술을 같이 시행했던 경우는 6명(10.3\%) 이었다. 한편, 35 명(60.3\%)의 환자는 입원하여 치료 받았으며 나머지 23명(39.7\%)은 통원치료를 받았다. 회복 여부에 따라 분류하면 38명(65.5\%)은 완전회복 되었으며, 11명(19.0\%)은 부분회복, 9명(15.5\%)은 끝까지 회복되지 않았다. 또한 회복되 었던 환자들 중 16 명(27.6\%)은 추후 비슷한 증상으로 재발하 였다(Table 1).

대조군과 비교했을 때 환자군에서 총 백혈구 수, 호중구 수, 호중구-림프구 비율과 혈소판-림프구 비율은 유의하게 높았 다 $(p=0.015,0.001,0.002,0.025)$. 이외의 혈액검사에서는 유 의한 차이를 보이는 항목은 없었다(Table 2).

Table 1. Demographics and clinical characteristics of patients with acute low tone sensorineural hearing loss

\begin{tabular}{lc}
\hline \multicolumn{1}{c}{ Variables } & $\mathrm{n}(\%)$ \\
\hline Age (year) & $38.0 \pm 14.5$ \\
Sex & $10(17.2)$ \\
Male & $48(82.8)$ \\
Female & $5.2 \pm 6.1$ \\
Onset of treatment (day) & \\
Associated symptoms & $18(31.0)$ \\
None & $25(43.1)$ \\
Tinnitus only & $5(8.6)$ \\
Dizziness only & $10(17.2)$ \\
Tinnitus \& dizziness & \\
Treatment & $32(55.2)$ \\
Oral steroids & $7(12.1)$ \\
Oral steroids+diuretics & $13(22.4)$ \\
Oral steroids+lTDx & $6(10.3)$ \\
Oral steroids+diuretics+lTDx & \\
Admission & $35(60.3)$ \\
Inpatient & $23(39.7)$ \\
Outpatient & \\
Recovery & $38(65.5)$ \\
Fully recovery & $11(19.0)$ \\
Partially recovery & $9(15.5)$ \\
Unrecovery & \\
Recurrence & $42(72.4)$ \\
None & $16(27.6)$ \\
Recur & \\
\hline$T D x:$ intra-tympanic dexamethasone & \\
\hline & \\
\hline
\end{tabular}

ITDx: intra-tympanic dexamethasone injection
회복 여부에 따라 회복군(완전회복군)과 비회복군(부분회 복군+비회복군)으로 나누어 비교해보았을 때, 비회복군에 비 해 회복군의 환자들이 나이가 더 어렸으며 증상시작부터 치료 시작까지의 기간이 더 짧았다 $(p=0.005,0.031)$. 하지만 다른 혈액검사 결과나 NLR, PLR 값은 두 군 사이에 유의한 차이 가 없었다(Table 3).

다음으로, 재발했던 군과 재발하지 않았던 군으로 나누어 비교해보았을 때, 나이나 여러 가지 혈액검사 결과상 통계학 적으로 유의한 차이를 보이는 항목은 없었다(Table 4).

\section{고 찰}

돌발성 난청과 급성 저음역 감각신경성 난청은 그 정도의 차이는 있지만 급성으로 발생하는 청력손실이라는 점에서 공 통 분모를 가지는 질병이다. 따라서 이 둘 사이의 경계가 명확 하지 않은 것이 사실이며, 치료 또한 경구 스테로이드를 쓴다 는 측면에서 같은 질병군으로 묶어 생각하기 쉽다. 하지만 증 상, 경과, 예후 등에서 서로 다른 특성을 보이며, 특히 어지럼 증이 동반된 급성 저음역 감각신경성 난청의 경우에는 메니에 르병의 초기 단계로 간주해야 한다는 의견이 더 많다. ${ }^{13,17)}$ 이 에 돌발성 난청과 급성 저음역 감각신경성 난청의 병인, 역학, 예후 등에 대해서 비교 분석하는 연구들이 나오고 있다. ${ }^{18-20)}$

한편, NLR, PLR은 염증 상태 및 혈전 발생에 대한 표지자 로서 여러 질환에서 그 의미가 부각되고 있다. 그 중에 이비인 후과 영역에서는 전정신경염이나 특발성 안면마비 등 발생 원 인이 불명확한 질환들에서 그 값이 증가되어 있으며 예후와 도 연관성이 있다는 연구들이 많다. ${ }^{21-23)}$ 돌발성 난청 또한 병 인으로 감염성 질환, 혈관 장애, 자가면역 질환 등이 제시되고 있으나 마찬가지로 아직 명확히 밝혀진 병인은 없다. ${ }^{24)}$ 최근 제 시되고 있는 돌발성 난청의 원인으로는 만성 염증과 혈전에 의한 허혈이 있는데, 혈액 점도의 증가와 염증성 반응이 귀의 미세순환계 손상을 일으키고 이것이 청력 손실을 일으킨다는

Table 2. Laboratory findings of the patient group and control group

\begin{tabular}{lccc}
\hline \multicolumn{1}{c}{ Variables } & $\begin{array}{c}\text { Patient group } \\
(n=58)\end{array}$ & $\begin{array}{c}\text { Control group } \\
(n=58)\end{array}$ & p value \\
\hline WBC & $8486 \pm 2797$ & $7387 \pm 1921$ & 0.015 \\
Platelet $(k)$ & $261.3 \pm 53.9$ & $268.3 \pm 55.1$ & 0.494 \\
Neutrophil & $5772 \pm 2802$ & $4298 \pm 1679$ & 0.001 \\
Lymphocyte & $2108 \pm 898$ & $2356 \pm 699$ & 0.100 \\
Monocyte & $476 \pm 258$ & $505 \pm 216$ & 0.512 \\
NLR & $4.04 \pm 4.43$ & $2.05 \pm 1.41$ & 0.002 \\
PLR & $164.8 \pm 119.5$ & $125.2 \pm 56.2$ & 0.025 \\
\hline
\end{tabular}

All parameters were expressed as mean \pm standard deviation. WBC: white blood cell, NLR: neutrophil-to-lymphocyte ratio, PLR: platelet-to-lymphocyte ratio 
NLR and PLR in Acute Low Tone SNHL I Kim KH, et al.

Table 3. Clinical characteristics and laboratory findings of the recovery group and non-recovery group

\begin{tabular}{lccc}
\hline \multicolumn{1}{c}{ Variables } & Recovery group $(\mathrm{n}=38)$ & Non-recovery group $(\mathrm{n}=20)$ & $\mathrm{p}$ value \\
\hline Age (year) & $34.2 \pm 12.4$ & $45.2 \pm 15.8$ & 0.005 \\
Onset of treatment (day) & $3.6 \pm 3.4$ & $8.3 \pm 8.7$ & 0.031 \\
WBC & $8384 \pm 2601$ & $8680 \pm 3201$ & 0.706 \\
Platelet (k) & $260.4 \pm 43.9$ & $263.2 \pm 70.5$ & 0.853 \\
Neutrophil & $5702 \pm 2355$ & $5906 \pm 3570$ & 0.795 \\
Lymphocyte & $2061 \pm 854$ & $2199 \pm 995$ & 0.583 \\
Monocyte & $483 \pm 258$ & $463 \pm 265$ & 0.776 \\
NLR & $3.70 \pm 3.20$ & $4.69 \pm 6.19$ & 0.513 \\
PLR & $160.2 \pm 100.3$ & $173.5 \pm 152.0$ & 0.689 \\
\hline
\end{tabular}

All parameters were expressed as mean \pm standard deviation. WBC: white blood cell, NLR: neutrophil-to-lymphocyte ratio, PLR: platelet-to-lymphocyte ratio

Table 4. Clinical characteristics and laboratory findings of the recurred group and non-recurred group

\begin{tabular}{lccc}
\hline \multicolumn{1}{c}{ Variables } & Non-recurred group $(\mathrm{n}=42)$ & Recurred group $(\mathrm{n}=16)$ & $\mathrm{p}$ value \\
\hline Age (year) & $36.9 \pm 15.3$ & $40.9 \pm 12.2$ & 0.349 \\
Onset of treatment (day) & $5.1 \pm 6.7$ & $5.6 \pm 4.6$ & 0.772 \\
WBC & $8407 \pm 2875$ & $8693 \pm 2662$ & 0.731 \\
Platelet (k) & $263.0 \pm 57.7$ & $257.2 \pm 43.7$ & 0.719 \\
Neutrophil & $5732 \pm 2869$ & $5880 \pm 2709$ & 0.859 \\
Lymphocyte & $2094 \pm 900$ & $2145 \pm 922$ & 0.849 \\
Monocyte & $463 \pm 247$ & $511 \pm 291$ & 0.526 \\
NLR & $4.00 \pm 4.58$ & $4.15 \pm 4.16$ & 0.913 \\
PLR & $165.4 \pm 118.4$ & $163.1 \pm 126.1$ & 0.948 \\
\hline
\end{tabular}

All parameters were expressed as mean \pm standard deviation. WBC: white blood cell, NLR: neutrophil-to-lymphocyte ratio, PLR: platelet-to-lymphocyte ratio

것이다. ${ }^{25)}$ 이것을 토대로 NLR, PLR이 염증 상태 및 혈전 발생 에 대한 표지자로 제시되었다. Özler ${ }^{26)}$ 는 돌발성 난청 환자에 서 NLR 값이 대조군에 비해 유의하게 높은 결과를 보인다고 하였으며, Seo 등 ㄱ) 은 NLR 뿐만 아니라 PLR 값도 돌발성 난 청 환자에서 대조군에 비해 높은 값을 보였다고 발표하였다. 또 다른 논문들에서는 이 표지자를 예후 예측 인자로서도 연 구하였는데, Ulu 등')은 NLR이 돌발성 난청 환자의 회복 정 도를 예측하는 인자로서 고려되어야 한다고 하였고, $\mathrm{Yi}$ 등이은 NLR 외에 PLR도 추후 돌발성 난청의 회복에 대한 예측인자 로 유용하다고 발표한 바 있다.

본 연구 결과에 따르면, 우선 급성 저음역 감각신경성 난청 환자와 대조군을 비교하였을 때 NLR, PLR 값은 환자군에서 유의하게 높게 나왔으며, 이는 기존 돌발성 난청과 NLR, PLR 값의 연관성을 연구했던 여러 논문들과 일치하는 결과였다. 이 에 돌발성 난청과 급성 저음역 감각신경성 난청이 염증 및 혈 전에 의한 허혈이라는 비슷한 병인을 가지고 있다고 예측할 수 있겠다. 또한, 총 백혈구 수를 보면 환자군과 대조군 사이에 유 의한 차이를 보였지만 그 절대값이 두 군 모두에서 10000 이 하로 정상범위였는데, 총 백혈구 수보다는 백혈구 분율 및 혈 소판 수를 반영하는 NLR, PLR 값이 만성 염증 및 허혈 상태
를 더 잘 나타내는 것으로 생각할 수 있다. 하지만 회복군과 비 회복군으로 나누어 분석하였을 때 NLR, PLR 값은 회복 정 도와 연관성이 떨어지는 것으로 나왔는데, 이런 결과는 돌발 성 난청에서의 경우와 달리 급성 저음역 감각신경성 난청에서 는 NLR, PLR 값이 회복 예측 인자로서는 그 의의가 떨어진 다는 것을 보여준다. 다만 유의한 차이는 없었지만 평균 값을 비교해보았을 때 회복군에서 NLR, PLR 값이 비회복군에 비 해 낮은 수치를 보였는데, 추후에 표본 수를 더 늘려 재분석 이 필요할 것으로 보인다.

추가로, 추후 재발했던 군과 재발하지 않았던 군으로 나누어 분석해보았으나 NLR, PLR 값은 두 군 사이에 유의한 차이가 없는 것으로 나왔다. 다른 연구들에서는 재발 여부와 NLR, PLR 값 사이의 연관성을 분석한 연구가 없어 비교하기 어렵 지만, 재발 여부를 반영한다고 보기에는 무리가 있다고 생각 된다.

Lee 등은 우리나라 정상인들의 NLR과 PLR 값의 평균 수치를 계산하였는데, 연령과 성별에 따라 조금씩 차이가 있 지만 전체적인 평균으로 NLR은 1.65, PLR은 132.4라고 제시 하였다. ${ }^{28-30)}$ 본 연구와 비교해보면, 이 평균 수치는 대조군의 수치와 비슷한 결과이며, 환자군은 이보다 높은 수치를 보였 
다. 이러한 정상인들의 평균 수치와의 비교 결과는 급성 저음 역 감각신경성 난청의 염증성 병인에 무게를 실어주는 결과 라고 생각할 수 있다.

본 연구의 제한점으로는 우선 단일기관에서 진단 받고 치 료 받은 환자들만을 대상으로 하여, 연구 표본 수가 비교적 적다는 점이다. 따라서 본 연구의 결과를 일반화시키기 위해 서는 전향적 연구를 통해 표본 수를 더 많이 늘려야 할 것으 로 생각된다. 둘째로, 환자군과 연령과 성별이 같은 환자들을 대조군으로 선정하였는데 대조군 선정에 어려움이 있어 일대 일 매칭을 사용하였는데, 이는 선택 비뚤림(selection bias)의 가능성이 있을 수 있다. 추후 연구에서는 더 많은 대조군을 확 보하고 성향점수 분석(propensity score analysis)을 이용하 여 대조군을 명확히 하는 과정이 필요할 것으로 보인다. 또 다 른 제한점으로, 다른 논문들에서 사용했던 진단기준을 살펴 보면 $125 \mathrm{~Hz}$ 가 포함된 경우가 많았으나, 본 병원에서는 순음 청력검사를 시행할 때 $125 \mathrm{~Hz}$ 의 주파수는 통상적으로 검사 하지 않기 때문에 저음역에 대한 좀더 세밀한 평가가 이루어 질 수 없었다.

결론적으로 돌발성 난청과 같이 급성 저음역 감각신경성 난청 환자에서도 호중구-림프구 비율과 혈소판-림프구 비율 이 대조군에 비해 상대적으로 높았다. 하지만 회복군과 비회 복군 사이에 유의한 차이는 없었으며, 재발 여부와도 상관관 계는 보이지 않았다. 따라서 급성 저음역 감각신경성 난청 환 자에서 높은 호중구-림프구 비율과 혈소판-림프구 비율은 그 염증성 병인을 반영한다고 볼 수 있으나, 예후 예측 인자 로서는 그 가치가 떨어진다고 볼 수 있다.

\section{Acknowledgments}

None.

\section{Author Contribution}

Conceptualization: Seung Hwan Lee, Jae Ho Chung. Data curation: Keon-Ho Kim, Byung Hun Kim, Seungyeol Lee. Formal analysis: Keon-Ho Kim, Hayoung Byun. Investigation: Byung Hun Kim, Seungyeol Lee. Methodology: Hayoung Byun, Jae Ho Chung. Supervision: Jae Ho Chung, Seung Hwan Lee. Writing-original draft: Keon-Ho Kim. Writing_review \& editing: Jae Ho Chung, Hayoung Byun, Seung Hwan Lee.

\section{ORCIDs}

Seung Hwan Lee

https://orcid.org/0000-0003-2001-7689

Jae Ho Chung

https://orcid.org/0000-0001-6884-7927

\section{REFERENCES}

1) Kuhn M, Heman-Ackah SE, Shaikh JA, Roehm PC. Sudden sensorineural hearing loss: A review of diagnosis, treatment, and prognosis. Trends Amplif 2011;15(3):91-105.

2) Masuda M, Kanzaki S, Minami S, Kikuchi J, Kanzaki J, Sato H, et al. Correlations of inflammatory biomarkers with the onset and prognosis of idiopathic sudden sensorineural hearing loss. Otol Neurotol 2012;33(7):1142-50.

3) Wang Q, Ma J, Jiang Z, Ming L. Prognostic value of neutrophil-tolymphocyte ratio and platelet-to-lymphocyte ratio in acute pulmonary embolism: A systematic review and meta-analysis. Int Angiol 2018; 37(1):4-11.

4) Hammad M, Shehata OZ, Abdel-Latif SM, El-Din AMM. Neutrophil/ lymphocyte ratio and platelet/lymphocyte ratio in Behçet's disease: Which and when to use? Clin Rheumatol 2018;37(10):2811-7.

5) Qin B, Ma N, Tang Q, Wei T, Yang M, Fu H, et al. Neutrophil to lymphocyte ratio (NLR) and platelet to lymphocyte ratio (PLR) were useful markers in assessment of inflammatory response and disease activity in SLE patients. Mod Rheumatol 2016;26(3):372-6.

6) Gasparyan AY, Ayvazyan L, Mukanova U, Yessirkepov M, Kitas GD. The platelet-to-lymphocyte ratio as an inflammatory marker in rheumatic diseases. Ann Lab Med 2019;39(4):345-57.

7) Templeton AJ, McNamara MG, Šeruga B, Vera-Badillo FE, Aneja $\mathrm{P}$, Ocaña A, et al. Prognostic role of neutrophil-to-lymphocyte ratio in solid tumors: A systematic review and meta-analysis. J Natl Cancer Inst 2014;106(6):dju124.

8) Paliogiannis P, Fois AG, Sotgia S, Mangoni AA, Zinellu E, Pirina $\mathrm{P}$, et al. Neutrophil to lymphocyte ratio and clinical outcomes in COPD: Recent evidence and future perspectives. Eur Respir Rev 2018;27(147):170113.

9) Ulu S, Ulu MS, Bucak A, Ahsen A, Yucedag F, Aycicek A. Neutrophilto-lymphocyte ratio as a new, quick, and reliable indicator for predicting diagnosis and prognosis of idiopathic sudden sensorineural hearing loss. Otol Neurotol 2013;34(8):1400-4.

10) Yi KI, Oh SJ, Choi SW, Kim SL, Kong SK, Goh EK. The significance of neutrophil-to-lymphocyte ratio and platelet-to-lymphocyte ratio as markers for prognosis in idiopathic sudden sensorineural hearing loss. Korean J Otorhinolaryngol-Head Neck Surg 2018; 61(7):333-40.

11) Stölzel K, Droste J, Voß LJ, Olze H, Szczepek AJ. Comorbid symptoms occurring during acute low-tone hearing loss (AHLH) as potential predictors of Menière's disease. Front Neurol 2018;9: 884.

12) Roh KJ, Lee EJ, Park AY, Choi BI, Son EJ. Long-term outcomes of acute low-tone hearing loss. J Audiol Otol 2015;19(2):74-8.

13) Lee SA, Lee SJ, Jung DY, Kim BG, Lee Ck, Choi SJ, et al. The comparison of short-term therapeutic effects of acute low-tone sensorineural hearing loss according to steroid capacity. Korean J Otorhinolaryngol-Head Neck Surg 2018;61(4):177-81.

14) Siegel LG. The treatment of idiopathic sudden sensorineural hearing loss. Otolaryngol Clin North Am 1975;8(2):467-73.

15) Sato H, Kuwashima S, Nishio SY, Kitoh R, Fukuda S, Hara A, et al. Epidemiological survey of acute low-tone sensorineural hearing loss. Acta Otolaryngol 2017;137(sup565):S34-7.

16) Seo HW, Lee HN, Jun HW, Byun H, Chung JH, Lee SH. Comparison of the treatment outcome between primary intratympanic steroid and salvage intratympanic steroid protocol in sudden sensorineural hearing loss: Propensity score matching analysis. Korean J Otorhinolaryngol-Head Neck Surg 2020;63(6):252-8.

17) Imamura $S$, Honda $H$, Miyata $M$, Mizukoshi $A$, Masuyama $K$. [Clinical statistics of recurrent acute low-tone senseorineural hearing loss]. Nihon Jibiinkoka Gakkai Kaiho 2007;110(7):520-6.

18) Yoshida T, Sone M, Kitoh R, Nishio SY, Ogawa K, Kanzaki S, et al. Idiopathic sudden sensorineural hearing loss and acute low-tone sensorineural hearing loss: A comparison of the results of a nationwide epidemiological survey in Japan. Acta Otolaryngol 2017;137(sup565): S38-43.

19) Mao Y, Wang W. [Clinical study of acute low-tone sensorineural hearing loss]. Lin Chuang Er Bi Yan Hou Ke Za Zhi 2006;20(13): $602-4$. 
20) Lin L, Tang A. [Clinical evaluation of acute low-tone sensorineural hearing loss]. Lin Chung Er Bi Yan Hou Tou Jing Wai Ke Za Zhi. 2011;25(16):738-40, 743.

21) Shushan S, Shemesh S, Ungar OJ, Cavel O, Handzel O, Tamir SO, et al. Neutrophil-to-lymphocyte ratio and platelet-to-lymphocyte ratio among patients with vestibular neuritis. ORL J Otorhinolaryngol Relat Spec 2019;81(5-6):304-8.

22) Oya R, Takenaka $Y$, Imai $T$, Sato $T$, Oshima $K$, Ohta $Y$, et al. Neutrophil-to-lymphocyte ratio and platelet-to-lymphocyte ratio as prognostic hematologic markers of Bell's palsy: A meta-analysis. Otol Neurotol 2019;40(5):681-7.

23) Atan D, İkincioğulları A, Köseoğlu S, Özcan KM, Çetin MA, Ensari S, et al. New predictive parameters of Bell's palsy: Neutrophil to lymphocyte ratio and platelet to lymphocyte ratio. Balkan Med J 2015;32(2):167-70.

24) Merchant SN, Adams JC, Nadol JB Jr. Pathology and pathophysiology of idiopathic sudden sensorineural hearing loss. Otol Neurotol 2005; 26(2):151-60.

25) Mosnier I, Stepanian A, Baron G, Bodenez C, Robier A, Meyer B, et al. Cardiovascular and thromboembolic risk factors in idiopathic sudden sensorineural hearing loss: A case-control study. Audiol
Neurootol 2011;16(1):55-66.

26) Özler GS. Increased neutrophil-lymphocyte ratio in patients with idiopathic sudden sensorineural hearing loss. J Craniofac Surg 2014;25(3):e260-3.

27) Seo YJ, Jeong JH, Choi JY, Moon IS. Neutrophil-to-lymphocyte ratio and platelet-to-lymphocyte ratio: Novel markers for diagnosis and prognosis in patients with idiopathic sudden sensorineural hearing loss. Dis Markers 2014;2014:702807.

28) Lee JS, Kim NY, Na SH, Youn YH, Shin CS. Reference values of neutrophil-lymphocyte ratio, lymphocyte-monocyte ratio, plateletlymphocyte ratio, and mean platelet volume in healthy adults in South Korea. Medicine (Baltimore) 2018;97(26):e11138.

29) Wu L, Zou S, Wang C, Tan X, Yu M. Neutrophil-to-lymphocyte and platelet-to-lymphocyte ratio in Chinese Han population from Chaoshan region in South China. BMC Cardiovasc Disord 2019; 19(1):125.

30) Moosazadeh M, Maleki I, Alizadeh-Navaei R, Kheradmand M, Hedayatizadeh-Omran A, Shamshirian A, et al. Normal values of neutrophil-to-lymphocyte ratio, lymphocyte-to-monocyte ratio and platelet-to-lymphocyte ratio among Iranian population: Results of Tabari cohort. Caspian J Intern Med 2019;10(3):320-5. 